\title{
LA CRÍTICA Y LA LIBERTAD DE OPINAR
}

\author{
Jorge Valenzuela Garcés \\ Universidad Nacional Mayor de San Marcos \\ jorgevalenzuela4@hotmail.com
}

En la segunda parte de su ensayo Sobre la libertad (1859), titulado "De la libertad de pensamiento y discusión" Mill se ocupa de la defensa de la libertad de opinión como el mecanismo más efectivo para hacerle frente a los gobiernos tiránicos y corruptos, pero también a cualquier tipo de fundamentalismo ideológico. Para Mill es inaceptable que cualquier gobierno o partido político quiera imponerle ideas a la sociedad y, peor aún, que considere que haciéndolo, le hace un bien. La libertad de opinión, dice Mill, es esencial para la democracia porque permite cambiar el error por la verdad o hacer que la verdad brille con la fuerza que le proporciona la evidencia.

Para Mill, la libertad de opinión permite que los seres humanos puedan desarrollar un juicio y puedan someter lo que creen al escrutinio de los que piensan lo contrario. Mill lo dice en estos términos: "La libertad completa de contradecir y desaprobar una opinión es la condición misma que nos justifica cuando la suponemos verdadera a los fines de la acción; y por ningún otro procedimiento puede el hombre llegar a tener seguridad racional de estar en lo cierto". Nadie, pues, tiene la verdad absoluta y cualquier negativa a la discusión, al acallar la libertad de opinar de los demás, supone una absurda infalibilidad, cuyo precio se paga con holocaustos sociales por todos conocidos. La actuación de ciertas organizaciones políticas extremistas sigue demostrando, como sostenía Mill, que cualquier verdad, cuando se sostiene en el espíritu sin la debida discusión racional, termina adoptando el semblante de un prejuicio y hasta de una superstición que, en el caso de la práctica política, puede llegar a ser letal como lo fue en el Perú hace treinta años. Por ello, para Mill, el cultivo de nuestro entendimiento debía consistir, esencialmente, en averiguar los fundamentos de nuestras propias opiniones, en primer término, como también el fundamento de las opiniones contrarias, sin proceder a su intolerante descalificación. De este modo, es decir, atendiendo a los fundamentos tanto en pro como en contra, las verdades que tenemos como tales bien pueden ser mejor comprendidas. Ese es el ejemplo de la dialéctica socrática, dice Mill, que consistía en una discusión negativa de las grandes cuestiones de la filosofía y de la vida, dirigida con un arte consumado a convencer a aquellos que meramente 
habían adoptado los lugares comunes de las doctrinas admitidas sin atender a sus verdaderos fundamentos o razones. Para Mill lo importante, y esa es también nuestra tarea, es que aquellos que son incapaces de cambiar lo hagan a la luz de las evidencias y que, finalmente, entiendan que una democracia estrictamente justa, en la que todos tenemos el derecho de discrepar, es esencial para nuestra supervivencia política. 